\title{
The Mediating Role of Coping between Competitive Anxiety and Sport Commitment in Adolescent Athletes
}

\author{
Joan Pons ${ }^{1}$, Carme Viladrich ${ }^{1}$, Yago Ramis ${ }^{1}$ and Remco Polman ${ }^{2}$ \\ 1 Universitat Autònoma de Barcelona (Spain). \\ ${ }^{2}$ Queensland University of Technology (Australia).
}

\begin{abstract}
Framed in cognitive-motivational-relational theory of emotions (Lazarus, 1999), this study aimed to test how coping mediated the relationship between competitive anxiety and sport commitment in a sample of adolescent athletes. Five-hundred adolescents $(M=16.42 ; S D=1.54)$ participated in our study. Participants completed competitive anxiety, coping, and sport commitment measures. We defined the measurement model using confirmatory factor analysis and exploratory structural equation modeling; and compared two different models of mediation (i.e., total and partial mediation) using structural equation modeling. Results favored partial mediation model where cognitive anxiety factors predicted sport commitment. Results from this model suggest direct and mediated structural relations between concepts. Somatic anxiety had a weak influence on sport commitment (total effects $=0.090[-.131, .311]$ ). Worry showed a positive influence on sport commitment (total effects $=.375[.262, .486]$ ) through direct and mediated effects. Concentration disruption showed a negative impact on sport commitment (total effects $=-.544[-.724,-.363]$ ) trough mediated effects only, showing a negative path on task-oriented coping and a positive path on disengagement-oriented coping. As a whole, our findings identify task coping efforts undertaken by adolescent athletes as a key element in the relationship between competitive anxiety and sport commitment. These findings provide preliminary evidence for the design of coping interventions in adolescents.
\end{abstract}

Received 10 February 2017; Revised 9 February 2018; Accepted 12 February 2018

Keywords: adaptability, emotions, factor analysis, motivation, stress.

Adolescence has been identified as a critical period for sport continuation, being the period where the greatest drop-out occurs. Many factors such as interpersonal constraints, lack of enjoyment, or perceptions of low competence have been associated with this phenomenon (for a review, Crane \& Temple, 2014). Emotions experienced during sport activities seem to have some importance in this regard (Mohiyeddini, Pauli, \& Bauer, 2009). Coping with these emotions is considered a relevant factor influencing adolescent experiences within their sport, both in a positive or in a negative way (Nicholls, Perry, Jones, Morley, \& Carson, 2013). Coping is defined as the "constantly changing cognitive and behavioral efforts to manage specific internal and/ or external demands that are appraised as taxing or exceeding the resources of the person" (Lazarus \& Folkman, 1984, p. 141).

Coping helps to regulate emotions generated by stressors. Specific coping strategies are often classified into task- and disengagement-oriented coping dimensions

\footnotetext{
Correspondence concerning this article should be addressed to Joan Pons. Facultat de Psicologia Bàsica, Evolutiva, i de l’Educació de la Universitat Autònoma de Barcelona. 08193 Bellaterra, Barcelona (Spain). E-mail: joan.pons.bauza@uab.cat

This project was supported by the Spanish Ministerio de Educación, Cultura y Deporte [grant number: FPU/00738].
}

(Gaudreau \& Blondin, 2004). Task-oriented coping (TOC) represents efforts oriented to directly deal with stressful situations, meanwhile disengagement-oriented coping (DOC) is understood as thoughts and behaviors that focus attention away from the stressful events. Given the prevalence of certain coping strategies in adolescent athletes (Nicholls, Levy, \& Perry, 2015; Nicholls et al., 2013), coping dimensions based on TOC (i.e., effort expenditure, thought control, and logical analysis strategies), and DOC (i.e., venting of emotions and resignation strategies) are of particular interest in our study. Although coping strategies and dimensions are not universally beneficial or detrimental (Lazarus, 1999), TOC typically predict more desirable consequences in adolescents (e.g., academic competence or psychological adjustment; Compas, Connor-Smith, Saltzman, Thomsen, \& Wadsworth, 2001).

From the cognitive-motivational-relational theory of emotions (CMRT; Lazarus, 1999), coping intertwine with cognitive appraisals and emotions. As this is a

How to cite this article:

Pons, J., Viladrich, C., Ramis, Y., \& Polman, R. (2018). The mediating role of coping between competitive anxiety and sport commitment in adolescent athletes. The Spanish Journal of Psychology, 21. e7. Doi:10.1017/sjp.2018.8 
recursive process, coping can both go before and after emotions (Lazarus, 1991). According to the theory, a person has a tendency to judge his or her personenvironment relationship in order to determine if the environment endangers or has the potential to threat personal goals. This process is known as primary appraisal. CMRT also posits that an additional evaluation (i.e., secondary appraisal) intercedes in this assessment process. Secondary appraisal identifies coping possibilities available for the person in that situation. Primary and secondary appraisals may be modulated over time due to habituation process (Tong et al., 2009). The combination of appraisals may result in four possible evaluations (i.e., harm/loss, threat, challenge, or benefit) which, in turn, generate emotions.

Lazarus (2000) defined emotions as "an organized psychophysiological reaction to ongoing relationships with the environment, most often, but not always, interpersonal or social" (p. 230). This author identified eight relevant emotions that arise in the domain of sport (i.e., anger, anxiety, shame, guilt, hope, relief, happiness, and pride). Of these emotions, competitive anxiety has received the most attention in the sport literature, and is believed to negatively influence sport continuation (Martens, Vealey, \& Burton, 1990). Competitive anxiety usually implies that an athlete appraises a situation as having personal significance, and perceives not having the resources to cope with the situation (Wolf, Evans, Laborde, \& Kleinert, 2015).

Martens (1977) defined competitive state anxiety as the "tendency to perceive competitive situations as threatening and to respond to them with feelings of apprehension and tension" (p. 23). These feelings include somatic and cognitive symptoms of anxiety (Martens et al., 1990). Somatic anxiety refers to "physiological and affective elements of the anxiety experience" (Martens et al., 1990, p.6). Regarding cognitive anxiety, some research (e.g., Ponseti, Sesé, \& Garcia-Mas, 2016; Wolf, Eys, \& Kleinert, 2015) has considered the division of cognitive anxiety components (i.e., worry and concentration disruption), which has shown differences in their relation with other constructs in adolescent athletes (Grossbard, Smith, Smoll, \& Cumming, 2009). Worry is conceptualized as non-optimistic concerns regarding potential negative personal and social consequences of poor performance (Sarason, 1984). Concentration disruption implies difficulties in focusing on task relevant cues and thinking clearly in competitive situation (Nideffer \& Sagal, 2006). This tri-dimensional distinction of competitive anxiety is part of a higher conceptual framework (Smith, 2008).

Morris and Kavussanu (2009) found that worry and concentration disruption in adolescents were negatively related with enjoyment. As enjoyment has strong associations with sport commitment (Garcia-Mas et al., 2010), we expect similar relations between competitive anxiety and sport commitment. Previous exploratory research has found no conclusive relations (Pons, Ramis, GarciaMas, de la Llave, \& Perez-Llantada, 2016). In this study, we aim to test this hypothesis from a stronger methodological approach. Sport commitment is defined as "the psychological construct representing the desire and resolve to continue sport participation" (Scanlan, Carpenter, Simons, Schmidt, \& Keeler, 1993, p. 6). Following CMRT, we expect that coping may play a mediating role (i.e., total or partial) in the relationship between competitive anxiety and sport commitment (Lazarus, 1999). Therefore, understanding the association of competitive anxiety, coping, and sport commitment might resolve whether specific coping orientations strengthens or mitigate the negative association between competitive anxiety and sport commitment.

Some, but not conclusive, research in the sport context has empirically supported the relations among these variables. Ntoumanis and Biddle (2000) observed that adolescents' intensity of cognitive anxiety symptoms was associated with DOC. Similarly, Hatzigeorgiadis and Chroni (2007) found negative associations between TOC and cognitive anxiety, and positive associations between somatic anxiety intensity and DOC. In addition, previous investigations have addressed the impact of coping on some other indicators of sport continuation such as burnout (e.g., Raedeke \& Smith, 2004). For example, Kim and Duda (2003) found that sport commitment was positively related with TOC among university students. These studies have investigated the relationships between emotions and coping, or between coping and indicators of sport continuation (i.e., sport commitment). However, few studies have examined the interplay between emotions, coping, and sport commitment among adolescents. Our study aims to shed some light on this gap in the literature by examining the mediating role of coping between competitive anxiety and sport commitment.

\section{Method}

\section{Participants}

Five-hundred team sport athletes participated in the study of which $36.8 \%$ were female. Athletes' ages were between 13 and $21(M=16.42 ; S D=1.54)$ pertaining to 56 teams. All participants were Spanish and practiced the following team sports: Basketball $(49.8 \%)$, soccer $(19.4 \%)$, volleyball $(14.6 \%)$, handball $(11.2 \%)$, roller hockey $(3.4 \%)$, and water polo $(1.6 \%)$.

\section{Measures}

Competitive anxiety was assessed with the Sport Anxiety Scale-2 (SAS-2; Smith, Smoll, Cumming, \& Grossbard, 2006), using the Spanish version (Ramis, Torregrosa, 
Viladrich, \& Cruz, 2010). This is a 15 -item questionnaire containing the subscales of somatic anxiety (e.g., "My body feels tense"), worry (e.g., "I worry that I will not play my best"), and concentration disruption (e.g., "I lose focus on the game"). All items were rated on a 4-point Likert-style scale. The scale had good reliability with Cronbach's alpha values of .83 for somatic anxiety, .84 for worry, and .81 for concentration disruption. Confirmatory factor analysis showed a good fit, with $\chi^{2}(87)=262.7, p<.001, \mathrm{RMSEA}=.064,90 \%$ CI [.055, .072], $\mathrm{CFI}=.965$, and TLI $=.958$.

Coping was assessed through the "Inventaire des Stratégies de Coping en Compétition Sportive" [Coping Inventory for Competitive Sport] (ISCCS; Gaudreau, \& Blondin, 2002). The Spanish version (Molinero, Salguero, \& Márquez, 2010) is composed of 31 items. We selected items from effort expenditure (e.g., "I apply myself by giving a consistent effort"), logical analysis (e.g., "I analyse my past performances"), thought control (e.g., "I try not to be intimidated by other athletes"), venting of emotions (e.g., "I get angry"), and resignation (e.g., "I let myself feel hopeless and discouraged") strategies, corresponding to TOC and DOC (Gaudreau \& Blondin, 2004). Cronbach's alpha values were .69 for TOC and .75 for DOC. Congruent with the idea defended by Lazarus (2006) that coping dimensions are not strictly task- or disengagement-oriented, we opted for a measurement model with less-restrictive conditions (i.e., Exploratory Structural Equation Model; ESEM). This showed a model fit of $\chi^{2}(76)=352, p<.001$, RMSEA $=$ $.085,90 \%$ CI $[.076, .094], \mathrm{CFI}=.865$, and TLI $=.801$.

Sport commitment was assessed through the commitment subscale of the Sport Commitment Questionnaire (SCQ; Scanlan et al., 1993), using the Spanish version (Sousa, Torregrosa, Viladrich, Villamarín, \& Cruz, 2007). This subscale is composed of six items (e.g., "I want to keep playing my sport this season"). All items were rated on a 5-point Likert-style scale. Cronbach's alpha was .79 for the present study. Confirmatory factor analysis showed an excellent fit in our study, $\chi^{2}(9)=$ $16.7, p<.001$, RMSEA $=.041,90 \%$ CI [.000, .072], CFI $=$ .995 , and TLI $=.992$.

\section{Procedure}

This study was granted ethical approval by the university ethics committee. We contacted sport clubs and sent them an information letter. A date was arranged to administer the questionnaires with all clubs that agreed to participate. Data was collected in the clubhouse or locker rooms of the participating clubs and at least one trained researcher was present. Completion of the questionnaires took approximately 20 minutes. Those participants who requested $(47.2 \%)$ were send a report with their main results.

\section{Data Analysis}

\section{Preliminary Analysis and Measurement Models}

The first step of data analysis included examining missing data, item distribution and testing possible multilevel design effects. The existence of deviant cases was also evaluated. In the second step, we estimated the measurement models. Due to the ordinal nature of subscales, we decided to use Weighted Least Squares Mean and Variance Adjusted (WLSMV) estimator in Mplus 7.0 software. Standard errors corrected for multilevel design effects were used. Goodness of fit was assessed with $\chi^{2}$, root mean square error of approximation (RMSEA), comparative fit index (CFI), and tucker lewis index (TLI). According to Yu (2002), CFI and TLI values $>.95$ and RMSEA $<.06$ are indicators of excellent fit for categorical data. We used confirmatory factor analysis (CFA), and exploratory structural equation modeling (ESEM) to define the measurement model for each questionnaire.

\section{Mediation Model}

We evaluated if TOC and DOC mediated the relationships between competitive anxiety components and sport commitment. We tested a model where only mediated effects were specified (total mediation model), and a model with direct and mediated effects specified (partial mediation model) using structural equation modeling (SEM). As total mediation is nested within a partial mediation model, we selected the most appropriate mediation model based on (a) goodnessof-fit indexes of each model; and (b) differences of fit between the nested models.

\section{Results}

\section{Descriptive Data and Measurement Model}

Missing data was $0.3 \%$ and consequently, no special difficulties associated with missingness were expected. Intraclass Correlation Coefficient (ICC) of some items was sizeable for the team cluster variable, ranging from .06 to .12 . To take into account the multilevel design effects we used TYPE $=$ COMPLEX option in Mplus. Cook's distance was below one for all participants, suggesting the absence of outliers. Some descriptive results of the sample are provided at Table 1.

With the aim to evaluate a whole measurement model, we first evaluated single measurement models for each instrument. After that, we tested the full measurement model including restrictive conditions (i.e., CFA) for competitive anxiety, and commitment factors; and lessrestrictive conditions (i.e., ESEM) for coping. The full measurement model achieved acceptable goodness of fit indices (see Table 2). 
Table 1. Descriptive Statistics of Study Sample $(n=500)$

\begin{tabular}{lccccccccc}
\hline & $M$ & $S D$ & Range & $\alpha$ & 1 & 2 & 3 & 4 & 5 \\
\hline 1. Somatic anxiety & 1.75 & 0.64 & $1-4$ & .83 & - & & & \\
2. Worry & 2.88 & 0.75 & $1-4$ & .84 & $.54^{* *}$ & - & & \\
3. C. disruption & 1.74 & 0.61 & $1-4$ & .81 & $.68^{* *}$ & $.40^{* *}$ & - & & \\
4. TOC & 3.40 & 0.70 & $1-5$ & .69 & .04 & $.24^{* *}$ & $-.23^{* *}$ & - & -.08 \\
5. DOC & 2.23 & 0.77 & $1-5$ & .75 & $.43^{* *}$ & $.25^{* *}$ & $.58^{* *}$ & $.59^{* *}$ & $-.34^{* *}$ \\
6. Commitment & 4.35 & 0.65 & $1-5$ & .79 & -.08 & $.21^{* *}$ & $-.33^{* *}$ & \\
\hline
\end{tabular}

Note: "C. Disruption" refers to Concentration disruption; "TOC" refers to task-oriented coping; "DOC" refers to disengagement-oriented coping; ${ }^{*} p<.05,{ }^{* *} p<.001$.

Table 2. Fit Indexes of Measurement and Mediation Models

\begin{tabular}{|c|c|c|c|c|c|}
\hline & $\chi^{2}$ & $d f$ & CFI & TLI & RMSEA $(90 \%$ CI) \\
\hline \multicolumn{6}{|l|}{ Measurement models } \\
\hline CFA competitive anxiety & $262.768^{* *}$ & 87 & .965 & .958 & $.064[.055, .072]$ \\
\hline ESEM coping & $351.996^{* *}$ & 76 & .856 & .801 & $.085[.076, .094]$ \\
\hline CFA commitment & $16.709^{* *}$ & 9 & .995 & .992 & $.041[.000, .072]$ \\
\hline Full measurement model & $848.797^{* *}$ & 545 & .946 & .938 & $.033[.029, .038]$ \\
\hline \multicolumn{6}{|l|}{ Mediation models } \\
\hline Total mediation model & $913.812^{* *}$ & 569 & .933 & .926 & $.035[.031, .039]$ \\
\hline Partial mediation model & $903.621^{* *}$ & 566 & .934 & .927 & $.035[.030, .039]$ \\
\hline
\end{tabular}

Note: ${ }^{*} p<.05,{ }^{* *} p<.001$.

\section{Mediation Model}

We tested total mediation and partial mediation models (see Table 2). Both models showed goodness of fit values close to excellence. Comparison of the two models was computed using DIFTEST option in Mplus, showing significant differences, $\chi^{2}(3)=14.6 ; p<.05$, so we opted to select the best fitting model (i.e., partial mediation model).

All statistically significant regression paths of the accepted model are presented in Figure 1. Indirect effects standard errors were computed using the delta method as bootstrapped standard errors are not available for complex data. All indirect effects are presented in Table 3. Competitive anxiety factors had a significant effect on TOC. Concentration disruption also had a positive significant effect on DOC. The coping dimensions had a differential impact on commitment. TOC showed a positive effect on commitment, and DOC showed negative effect. Finally, there was a direct effect of worry on commitment. Results suggest that coping partially mediates the relationship between worry and sport commitment.

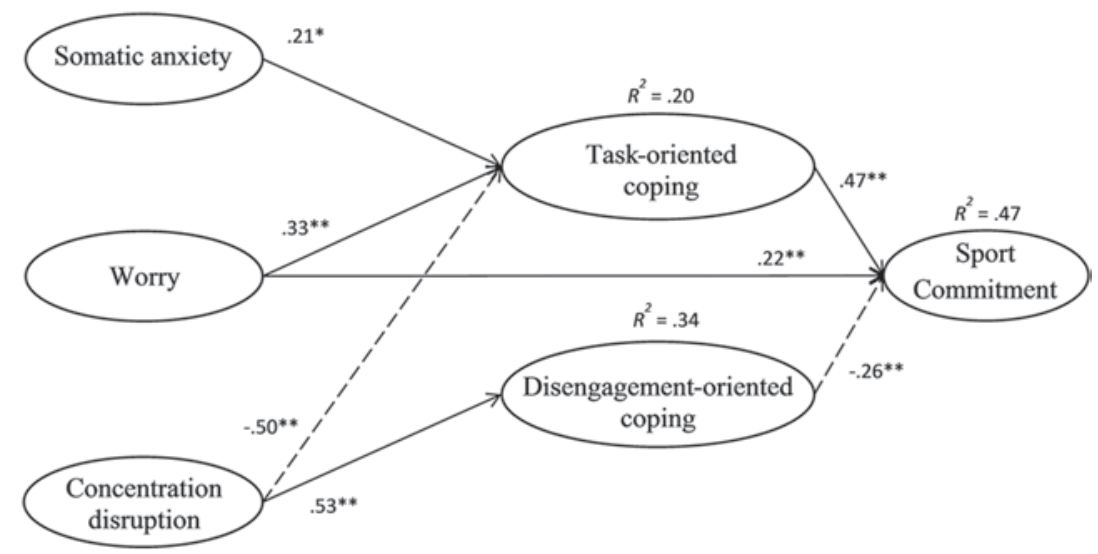

Figure 1. Structural equation model of the accepted model.

Note: Continuous lines indicate positive predictions and dashed lines indicate negative relationships. ${ }^{*} P<.05 .{ }^{* *} P<.001$. 
Table 3. Standardized Total and Indirect Effects for the Accepted Model.

\begin{tabular}{|c|c|c|c|c|c|c|}
\hline & \multicolumn{2}{|l|}{ Total } & \multicolumn{2}{|c|}{ Total indirect } & \multicolumn{2}{|c|}{ Specific indirect } \\
\hline & Estimate & $95 \% \mathrm{CI}$ & Estimate & $95 \% \mathrm{CI}$ & Estimate & $95 \% \mathrm{CI}$ \\
\hline Somatic anxiety $\rightarrow$ Commitment & .090 & {$[-.131, .311]$} & .081 & {$[-.021, .182]$} & & \\
\hline TOC & & & & & .100 & {$[.013, .188]$} \\
\hline DOC & & & & & -.020 & {$[-.069, .030]$} \\
\hline Worry $\rightarrow$ Commitment & .375 & {$[.262, .486]$} & .153 & {$[.072, .234]$} & & \\
\hline TOC & & & & & .154 & {$[.085, .223]$} \\
\hline DOC & & & & & -.001 & {$[-.035, .034]$} \\
\hline Concentration disruption $\rightarrow$ Commitment & -.544 & {$[-.724,-.363]$} & -.376 & {$[-.507,-.245]$} & & \\
\hline TOC & & & & & -.238 & {$[-.340,-.135]$} \\
\hline DOC & & & & & -.138 & {$[-.206,-.070]$} \\
\hline
\end{tabular}

Note: "TOC" refers to task-oriented coping; "DOC" refers to disengagement-oriented coping.

\section{Discussion}

This study assessed the mediating role of coping in the relation between competitive anxiety and sport commitment in adolescent athletes adopting the CMRT perspective. We tested two models where coping totally or partially mediated the relationship between competitive anxiety and sport commitment. Our results suggest that the partial mediation model better explained the interplay between competitive anxiety, coping and sport commitment in comparison to total mediation model. These findings support and extend previous research regarding the relation between these concepts (e.g., Kim \& Duda, 2003; Morris \& Kavussanu, 2009; Ntoumanis \& Biddle, 2000; Pons et al., 2016).

Previous literature found that competitive anxiety had a negative impact on adolescents' predisposition to keep participating in sport (Morris \& Kavussanu, 2009; Pons et al., 2016). In this study, competitive anxiety showed both positive and negative influences on sport commitment. Somatic anxiety had a weak influence on sport commitment; meanwhile cognitive anxiety components (i.e., worry and concentration disruption) showed important positive and negative influences on sport commitment. These results retake the traditional debate regarding the debilitative or facilitative role of competitive anxiety in sport competition (Jones \& Swain, 1995). Our study suggests that different components may have a positive or negative impact on sport competition. Even when competitive anxiety has traditionally been considered as detrimental, it has been suggested that anxiety may have positive effects on competition, favoring sustained effort and concertation on the task (e.g., Lazarus, 2000), and helping to re-appraise it as excitement (Brooks, 2014).

This study suggests that, in particular, the cognitive anxiety components predict sport commitment directly and indirectly through coping. Worry showed a positive direct effect on sport commitment. Greater worry was associated with more use of TOC that enhanced levels of sport commitment. Concentration disruption on the other hand was associated with greater use of DOC and less use of TOC, which in turn lowered sport commitment. Present findings suggest that those adolescents who take direct actions (i.e., effort, thinking about possible solutions, and controlling own thoughts) to face inherent demands of the competition are more likely to keep participating within their sport. This is consistent with the postulation that TOC might be associated with more desirable outcomes (Compas, et al., 2001).

Worry had positive direct and indirect (through TOC) effects on sport commitment. This finding is not in line with previous suggestions that higher levels of worry are associated with decreased TOC (e.g., Dias, Cruz, \& Fonseca, 2012) and lower sport enjoyment (Morris \& Kavussanu, 2009). Although the traditional conceptualization of worry describes it as a negative element of competitive anxiety (Nideffer \& Sagal, 2006), previous findings on the use of the Spanish version of the SAS-2 suggest that Worry may be conceptualized by young athletes as "a sense of responsibility regarding the task at hand" (Ramis, Viladrich, Sousa, \& Jannes, 2015). This conceptualization links with CMRT's primary appraisal definition (i.e., personal relevance of a situation; Lazarus, 1999), and share some nuances with the concept of perfectionistic strivings (i.e., setting of very high standards of performance; Stoeber, 2011). Similar to the findings of this study, recent research (Jowett, Hill, Hall, \& Curran, 2016) found perfectionist strivings acted as enhancer of athlete engagement and as protective factor for athlete burnout. Therefore, both concepts could share some psychological processes. Future studies should investigate about the nuances of each concept and the meaning and psychological process they share. 
Higher levels of concentration disruption where associated with increased use of DOC and less use of TOC which in turn reduced sport commitment. These findings are congruent with preliminary results presented by Dias et al. (2012). Previous research has also indicated that concentration disruption may limit attentional resources available for current task processing (Allen, Jones, McCarthy, Sheehan-Mansfield, \& Sheffield, 2013). Concentration disruption may threat attentional focus on the task at hand, which would interfere with the mobilization of resources for confronting competition demands, detracting attention from relevant cues of the task (i.e., TOC) and favoring the attention on alternative cues (e.g., DOC). This process might suggest that concentration disruption and DOC share some attentional resources. This idea is congruent with previous research (e.g., Carver, 2001) that suggest that anxiety may be useful in directing movement away from threats, by encouraging athletes to mobilize resources to achieve their goals.

From a practical perspective, our results suggest that future interventions based on coping fundamentals should focus on providing adolescent athletes with strategies to lower concentration disruption manifestations. In addition, training adolescent to use TOC might help them to deal with competitive anxiety in sport, and coaches might learn to judge athletes' emotional expression not only by their external expression (i.e., somatic anxiety) but also for cognitive indicators. This in turn is likely to enhance sport commitment among adolescents and lower future drop-out from sport.

Some limitations and future directions of this research must be addressed. As this is a cross-sectional study, no causal inferences can be made from our results. We acknowledge that conclusions drawn here are culturally dependent. Some studies suggest differences in coping processes among cultures (e.g., oriental versus occidental; Laborde, You, Dosseville, \& Salinas, 2012). We also consider that coping actions are influenced by type of sport. In this study participants mainly practiced opposition sports so future studies should also consider other sports with other requirements (e.g., exhibition or repetition). Given the difficulties in conducting factorial analysis with coping (Perry, Nicholls, Clough, \& Crust, 2015), future studies should explore alternative approaches (e.g., Pons, Viladrich, \& Ramis, 2017). Furthermore, although the SAS-2 has good psychometric properties, it would be important to further examine its functional, conceptual, and/or psychometric equivalence in different ethnic or cultural groups. This would be particularly important for the worry factor. Finally, in this study, we only selected those coping behaviors of interest for our current objectives, so we acknowledge the comparability issues with other works that used the full instrument.
Present results suggest that competitive anxiety has a relevant association with sport commitment. Specially, cognitive anxiety factors seem to differ in their influence on adolescent sport commitment. This relationship is mediated by athletes' style of coping. Coping oriented to task issues such as increase of effort, analysis of the situation, and control of own thoughts seem to strengthen this relation in a positive way. Alternatively, coping strategies diverting attention away from the stressful events, such as venting unpleasant emotions or resignation, might negatively influence sport continuation.

\section{References}

Allen M. S., Jones M., McCarthy P. J., Sheehan-Mansfield S., \& Sheffield D. (2013). Emotions correlate with perceived mental effort and concentration disruption in adult sport performers. European Journal of Sport Science, 13, 697-706. https:/ /doi.org/10.1080/17461391.2013.771381

Brooks A. W. (2014). Get excited: Reappraising pre-performance anxiety as excitement. Journal of Experimental Psychology: General, 143, 1144-1158. https: / / doi.org/10.1037/a0035325

Carver C. S. (2001). Affect and the functional bases of behavior: On the dimensional structure of affective experience. Personality and Social Psychology Review, 5, 345-356. https:/ / doi.org/10.1207/S15327957PSPR0504_4

Compas B. E., Connor-Smith J. K., Saltzman H., Thomsen A. H., \& Wadsworth M. E. (2001). Coping with stress during childhood and adolescence: Problems, progress, and potential in theory and research. Psychological Bulletin, 127, 87-127. https:/ / doi. org/10.1037//0033-2909.127.1.87

Crane J., \& Temple V. (2014). A systematic review of dropout from organized sport among children and youth. European Physical Education Review, 21, 114-131. https:/ / doi. org $/ 10.1177 / 1356336 X 14555294$

Dias C., Cruz J. F., \& Fonseca A. M. (2012). The relationship between multidimensional competitive anxiety, cognitive threat appraisal, and coping strategies: A multi-sport study. International Journal of Sport and Exercise Psychology, 10, 52-65. https:/ / doi.org/10.1080/1612197X.2012.645131

Garcia-Mas A., Palou P., Gili M., Ponseti X., Borras P. A., Vidal J., ... Sousa C. (2010). Commitment, enjoyment and motivation in young soccer competitive players. The Spanish Journal of Psychology, 13, 609-616. https: / / doi.org/10.1017/S1138741600002286

Gaudreau P., \& Blondin J.-P. (2002). Development of a questionnaire for the assessment of coping strategies employed by athletes in competitive sport settings. Psychology of Sport and Exercise, 3, 1-34. https: / / doi. org/10.1016/S1469-0292(01)00017-6

Gaudreau P., \& Blondin J.-P. (2004). Different athletes cope differently during a sport competition: A cluster analysis of coping. Personality and Individual Differences, 36, 1865-1877. https://doi.org/10.1016/j.paid.2003.08.017

Grossbard J. R., Smith R. E., Smoll F. L., \& Cumming S. P. (2009). Competitive anxiety in young athletes: Differentiating 
somatic anxiety, worry, and concentration disruption. Anxiety, Stress \& Coping, 22, 153-166. https://doi. org/10.1080/10615800802020643

Hatzigeorgiadis A., \& Chroni S. (2007). Pre-competition anxiety and in-competition coping in experienced male swimmers. International Journal of Sports Science and Coaching, 2, 181-189. https://doi.org/10.1260/ 174795407781394310

Jones G., \& Swain A. (1995). Predispositions to experience debilitative and facilitative anxiety in elite and nonelite performers. The Sport Psychologist, 9, 201-211. https:/ / doi. org/10.1123/tsp.9.2.201

Jowett G. E., Hill A. P., Hall H. K., \& Curran T. (2016). Perfectionism, burnout and engagement in youth sport: The mediating role of basic psychological needs. Psychology of Sport and Exercise, 24, 18-26. https:/ / doi. org/10.1016/j.psychsport.2016.01.001

Kim M.-S., \& Duda J. L. (2003). The coping process: Cognitive appraisals of stress, coping strategies, and coping effectiveness. The Sport Psychologist, 17, 406-425. https://doi.org/10.1123/tsp.17.4.406

Laborde S., You M., Dosseville F., \& Salinas A. (2012). Culture, individual differences, and situation: Influence on coping in French and Chinese table tennis players. European Journal of Sport Science, 12, 255-261. https:/ /doi. org/10.1080/17461391.2011.566367

Lazarus R. S. (1991). Progress on a cognitive-motivationalrelational theory of emotion. American Psychologist, 46, 819-834. https: / / doi.org/10.1037/ / 0003-066X.46.8.819

Lazarus R. S. (1999). Stress and emotion. A new synthesis. New York, NY: Springer.

Lazarus R. S. (2000). How emotions influence performance in competitive sports. The Sport Psychologist, 14, 229-252. https://doi.org/10.1123/tsp.14.3.229

Lazarus R. S. (2006). Emotions and interpersonal relationships: Toward a person-centered conceptualization of emotions and coping. Journal of Personality, 74, 9-46. https:/ / doi. org/10.1111/j.1467-6494.2005.00368.x

Lazarus R. S., \& Folkman S. (1984). Stress, appraisal and coping. New York, NY: Springer.

Martens R. (1977). Sport competition anxiety test. Champaign, IL: Human Kinetics.

Martens R., Vealey R. S., \& Burton D. (1990). Competitive anxiety in sport. Champaign, IL: Human Kinetics.

Mohiyeddini C., Pauli R., \& Bauer S. (2009). The role of emotion in bridging the intention-behavior gap: The case of sports participation. Psychology of Sport and Exercise, 10, 226-234. https://doi.org/10.1016/j.psychsport.2008.08.005

Molinero O., Salguero A., \& Márquez S. (2010). Propiedades psicométricas y estructura dimensional de la adaptación española del Cuestionario de Estrategias de Afrontamiento en Competición Deportiva [Psychometric properties and dimensional structure of the Spanish adaptation of the Coping Inventory for Competitive Sport]. Psicothema, 22, 975-982.

Morris R. L., \& Kavussanu M. (2009). The role of approachavoidance versus task and ego goals in enjoyment and cognitive anxiety in youth sport. International Journal of Sport and Exercise Psychology, 7, 185-202. https://doi.org/ 10.1080/1612197X.2009.9671899
Nicholls A. R., Levy A. R., \& Perry J. L. (2015). Emotional maturity, dispositional coping, and coping effectiveness among adolescent athletes. Psychology of Sport and Exercise, 17, 32-39. https://doi.org/10.1016/j. psychsport.2014.11.004

Nicholls A. R., Perry J. L., Jones L., Morley D., \& Carson F. (2013). Dispositional coping, coping effectiveness, and cognitive social maturity among adolescent athletes. Journal of Sport \& Exercise Psychology, 35, 229-238. https://doi.org/10.1123/jsep.35.3.229

Nideffer R. M., \& Sagal M.-S. (2006). Concentration and attention control training. In J. M. Williams (Ed.), Applied Sport Psychology: Personal Growth to Peak Performance $\left(5^{\text {th }}\right.$ Ed, pp. 382-403). Boston, MA: McGraw-Hill.

Ntoumanis N., \& Biddle S. J. H. (2000). Relationship of intensity and direction of competitive anxiety with coping strategies. The Sport Psychologist, 14, 360-371. https:/ / doi. org/10.1123/tsp.14.4.360

Perry J. L., Nicholls A. R., Clough P. J., \& Crust L. (2015). Assessing model fit: Caveats and recommendations for confirmatory factor analysis and exploratory structural equation modeling. Measurement in Physical Education and Exercise Science, 19, 12-21. https: / / doi.org/10.1080/ 1091367X.2014.952370

Pons J., Ramis Y., Garcia-Mas A., de la Llave A. L., \& Perez-Llantada M. C. (2016). Percepción de la ansiedad competitiva en relación al nivel de cooperación y compromiso deportivo en jugadores de baloncesto de formación [Perception of competitive anxiety in relation to cooperation level and sport commitment upon formative basketball players]. Cuadernos de Psicología del Deporte, 16, 45-54.

Pons J., Viladrich C., \& Ramis Y. (2017). Examining the big three of coping in adolescent athletes using network analysis as an alternative to factorial approach. Revista de Psicología del Deporte, 26, 68-74.

Ponseti X., Sesé A., \& Garcia-Mas A. (2016). The impact of competitive anxiety and parental influence on the performance of young swimmers. Revista Iberoamericana de Psicología del Ejercicio y el Deporte, 11, 229-237.

Raedeke T. D., \& Smith A. L. (2004). Coping resources and athlete burnout: An examination of stress mediated and moderation hypotheses. Journal of Sport \& Exercise Psychology, 26, 525-541. https:/ / doi.org/10.1123/jsep.26.4.525

Ramis Y., Torregrosa M., Viladrich C., \& Cruz J. (2010). Adaptación y validación de la versión española de la Escala de Ansiedad Competitiva SAS-2 para deportistas de iniciación [Adaptation and validation of the Spanish version of the Sport Anxiety Scale SAS-2 for young athletes]. Psicothema, 22, 1004-1009.

Ramis Y., Viladrich C., Sousa C., \& Jannes C. (2015). Exploring the factorial structure of the Sport Anxiety Scale-2: Invariance across language, gender, age and type of sport. Psicothema, 27, 174-181. https://doi. org/10.7334/psicothema2014.263

Sarason I. G. (1984). Stress, anxiety and cognitive interference: Reactions to tests. Journal of Personality and Social Psychology, 46, 929-938. https://doi.org/10.1037/0022-3514.46.4.929

Scanlan T. K., Carpenter P. J., Simons J. P., Schmidt G. W., \& Keeler B. (1993). An introduction to the Sport Commitment 
Model. Journal of Sport \& Exercise Psychology, 15, 1-15. https://doi.org/10.1123/jsep.15.1.1

Smith R. E. (2008). Advances in cognitive-social-personality theory: Applications to sport psychology. Revista de Psicología del Deporte, 17, 253-276.

Smith R. E., Smoll F. L., Cumming S. P., \& Grossbard J. R. (2006). Measurement of multidimensional sport performance anxiety in children and adults: The Sport Anxiety Scale-2. Journal of Sport E Exercise Psychology, 28, 479-501. https:/ / doi.org/10.1123/jsep.28.4.479

Sousa C., Torregrosa M., Viladrich C., Villamarín F., \& Cruz J. (2007). The commitment of young soccer players. Psicothema, 19, 256-262.

Stoeber J. (2011). The dual nature of perfectionism in sports: Relationships with emotion, motivation, and performance. International Review of Sport and Exercise Psychology, 4, 128-145. https://doi.org/10.1080/1750984x.2011.604789

Tong E. M. W., Bishop G. D., Enkelmann H. C., Why Y. P., Diong S. M., Khader M., \& Ang J. (2009). Appraisal underpinnings of affective chronometry: The role of appraisals in emotion habituation. Journal of Personality, 77, 1103-1136. https://doi.org/10.1111/j.1467-6494. 2009.00576.x

Wolf S. A., Evans M. B., Laborde S., \& Kleinert J. (2015). Assessing what generates precompetitive emotions: Precompetitive appraisal measure. Journal of Sports Sciences, 33, 579-587. https:/ / doi.org/10.1080/ 02640414.2014 .951873

Wolf S. A., Eys M. A., \& Kleinert J. (2015). Predictors of the precompetitive anxiety response: Relative impact and prospects for anxiety. International Journal of Sport and Exercise Psychology, 13, 334-358. https://doi.org/10. 1080/1612197X.2014.982676

Yu C.-Y. (2002). Evaluating cutoff criteria of model fit indices for latent variable models with binary and continuous outcomes (Published doctoral dissertation). University of California, CA. Retrieved from https://www.statmodel.com/papers_date. shtml 